\title{
Obesity Warning for Police Officers
}

\section{Abstract:}

Police officers are law-abiding citizens who wear a uniform to enforce the laws. They have the right to remain obese, but it can and will be used against them in the line of duty. This study discusses the need for police departments to institute programs that prepare and maintain healthy officers who can perform their jobs well throughout their careers. The study reveals the absolute need for police officers to be physically and mentally fit and argues that obese and unfit officers are dangers to themselves and to the public. Recommendations are made for police departments and officers to utilize in recruiting and training future officers and in educating veteran officers in order to maintain healthy and fit police officers. Although society is responsible for the kind of police it chooses to have, but policing is a physically demanding occupation and too important to be left to the unfit individuals.

Key Words: Policing; Physically Fit; Obesity; Danger

\section{Council for Innovative Research}

Peer Review Research Publishing System

\section{Journal: Journal of Social Sciences Research}

Vol. 6, No.3

jssreditor.cir@gmail.com

www.jssronline.com 


\section{Introduction:}

Police officers' injuries and deaths in the line of duty have long been treated as professionals' hazards. Unique casual processes have been identified to answer the question of why some officers get killed in the line of duty and why some officers are quick to use deadly force against aggressive suspects. Most police officers work long and hard. They care about enforcing the law and protecting society. However, when we subject the quality of their collective work as law enforcers to the same close examination we demand from other fields/disciplines, we find a substantial body of evidence that clearly demonstrates unsatisfactory performances from some of our nation's police forces.

These unsatisfactory performances should evoke a serious and determined response from each and every police department. Yet, rather than a strong need of urgency for change, some departments tend to ignore the unfitness and obesity problems within their ranks. Yet, the problem of obesity and unfitness of officers needs urgent responses. Police departments need to begin immediately to evaluate and improve the physical fitness quality of their police officers. Fortunately, this improvement is as possible as it is urgent. The professional research literature in public health, nutrition and physical education can easily provide valuable information that can be used to further understand more fully the how and why all humans and specifically police officers should remain physically fit. Community expects and physicians are of the opinion that all law enforcement (police) officials should be physically, emotionally and mentally fit at all times (Blum 2008, CDC 2009, Quigley 2008). Yet, the obese and unfit officers do not meet this standard.

\section{Obesity Defined:}

The relationship between height and weight is the best method used to determine if someone is obese. It is important to differentiate overweight and obese. According to the National Institutes of Health $(\mathrm{NIH})$, overweight is the increased body weight that is at least 10 percent over a recommended weight relative to the individual. The body mass index (BMI) is the most commonly used method of adjusting an index of weight for the height of a person. This research used this method to select respondents for this study. BMl is measured by dividing a person's weight in (kilograms) by height in (meters) squared "weight $(\mathrm{kg}) /$ height $(\mathrm{mt})$ ". It may also be calculated in pounds and inches, by multiplying weight in pounds by 704.5, the result divided by height in inches, and then, the second time, divide the result by height in inches, (National Institutes of Health $(\mathrm{NIH})$.

The National Institutes of Health (NIH) declared that a BMI of 25 to $29.9 \mathrm{~kg} / \mathrm{m}^{2}$ is overweight, while a BMl of $30 \mathrm{~kg} / \mathrm{m}^{2}$ or greater is obese. According to U.S. Department of Health and Human Services (2007), one problem with using BMI as the only tool is that very muscular individuals and the elderly who have lost muscle mass may be mis-categorized. For the purpose of this study, obesity is a range of weight that is greater than what is generally considered healthy for a given height, which is an adult who has a BMI of 30 or higher (Center for Disease Control and Prevention, CDC 2009) and is considered to be unfit. Generally, weight classification is as follows - obese is classified as adult individuals with a BMI > 30 .

\section{Problem Statement:}

Law enforcement is a stressful job and it requires that officers establish lifelong wellness habits. According to Collingwood (1998), a study of randomly sampled 1700 officers from different police departments across the United States, compared police officers average fitness levels with the general population. The result shows that police officers' average fitness levels are below the general public in the areas of aerobic fitness, body fat and abdominal strength, and average in upper body strength and lower back flexibility. The result of the study clearly shows that law enforcement officers are less fit in most areas than at least half of all United States citizens even though police jobs require that officers be more fit than an average citizen, (Quigley 2008 p. 1-2).

The issue of unfit and obese police officers has been a major concern for police administrators. Former Wichita Deputy Police Chief Paul Goward wrote a memo to his officers stating, "If you are unfit, do yourself and everyone else a favor. See a professional about a proper diet and a fitness training program, quit smoking, limit alcohol intake -- Don't mean to offend, this is just straight talk. I owe it to you" (Reeves 2006 p. 1). According to Shell (2005), "unique work demands a corresponding stress level and increasingly requires that those in the law enforcement profession establish lifelong wellness habits". One 40-year longitudinal study from 1950 through 1990 found that, appallingly, the life expectancy of a (unfit) retired male police officer in the United States was 66 years (p. 2). The cost for illness, injuries and diseases associated with unfitness is very high. For example, costs for law enforcement officers include heart diseases, at $\$ 183$ billion; and arthritis, $\$ 65$ billion (Shell 2005, p. 2).

T. J. Jurkanin of Illinois Law Enforcement Training and Standards Board states, "It has been well documented that law enforcement personnel, as an occupational class, have serious health risk problems in terms of cardiovascular disease, lower back disorders, and obesity. The unfit officer is less able to respond fully to strenuous physical activity, consequently, the risk of not performing physical duties is increased", $(2008$, p. 1). It is obvious that unfit and obese officers would not be able to engage a suspect in a sustained dragging, punching, running, lifting, pulling, crawling, etc, which are all expected to occur in a law enforcement officer's daily duties. An unfit and obese officer may resort to unnecessary use of deadly force as in the case of Parker v. District of Columbia (1988). Donald Parker was shot by a D. C. Metropolitan Police Department officer. Mr. Donald Parker was arrested on a warrant, but was allowed to get into his bedroom to get dressed, and in the process he escaped through a bedroom window. In an attempt to capture Parker, an unsuccessful pursuit ensued, which resulted in Mr. Parker being shot twice by Officer Hayes. Donald Parker sustained serious permanent injury (Parker v. District of Columbia 1988 p. 711). 
In Parker v. District of Columbia, Parker alleged that lack of a proper physical training program for D.C Metropolitan officers constituted deliberate indifference to his civil rights that resulted in the violation of his constitutional right. The U.S. Court of Appeals upheld Parker's favorable jury verdict and states "it is undisputed that Officer Hayes had no physical training for four years prior to the Parker incident. Given Officer Hayes physical condition, it is not hard to fathom that his most effective method for subduing the subjects of his pursuits would be the use of a firearm, as opposed to the application of physical force. Officer Hayes simply was not in adequate physical shape" (Parker v. District of Columbia 1988 p. 713). It is very clear to everyone that policing is a physically demanding occupation and that physical demanding occupation requires physical fitness as a bona fide occupational qualification, (Brooks 2000). Hence, Federal, State and Local Law Enforcement Departments can be held liable for hiring and keeping of unfit and obese police officers under state tort law with the waiver of sovereign immunity.

\section{Previous Studies:}

The available literature on obesity and the effect on law enforcement officers is at best discontinuous and without compelling theoretical perspective that allows full explanation of obesity in policing and its meaningful control. The studies reviewed for this paper consistently show that physical fitness has a direct impact on reducing injuries and improving personal well-being, as well as work performance in policing, (Quigley 2008; Brook 2000, and Jurkanin 2008 and Shell 2005). There are decades of research showing that FBI has trained law enforcement professionals and, in the process, has created a testament to the importance of physical, mental, and psychological preparedness for law enforcement officers. As an occupation, law enforcement holds the distinction of having the highest rate of heart disease, diabetes and suicide out of 149 professions and unfortunately there is strong statistical belief of the importance of physical fitness in the law enforcement profession, (Ebling 2002). A poll, taken online of well over 300,000 respondents one week after the firing of the police chief for promoting fitness in his department, showed overwhelming support for the ex-chief. Asked if the "jelly bellies" memo was inappropriate, 72 percent said "no" and only 28 percent agreed. Asked if, "You think the chief should have been fired for promoting fitness, the results were startling: only 3 percent said "yes" versus 97 percent "no", (Ardell 2006).

Also, Ebling (2002) observed that "while most law enforcement agencies recognize the importance of physical fitness for their officers and encourage them to exercise and maintain an adequate level of fitness, many find it difficult to implement a fitness program", (p. 4). In general, prior research on obesity and law enforcement, officials have failed to make a compelling argument to show that policing is a highly stressful occupation due to factors like changes in shift, conflict with citizens, high risk of danger and even courtroom responsibilities, hence, there is a serious need for officers to remain physically fit at all times.

\section{Theoretical Perspective:}

Obese law enforcement officers are not the "problem", they are the consequence of the problem. Obesity in law enforcement is not only real, but it has been established to be hazardous to everything the organization stands for and represents. Every officer needs to be aware that the image they convey is important and recognize that their appearance and demeanor in uniform is a primary factor in how (community) others perceive them. This study reveals that law enforcement administrators, and lawmakers are all part of the problem and that officers' obesity is the symptom.

Applying the "melting fat" concept of behavior, which states that the melting process depends on the temperature and will not stop until the temperature is appropriate for such action or inaction, (Otu 2011). Law enforcement officers who are obese must consider the policy of the organization in terms of their ability to get away with their appearance. They must also consider how their job is defined relative to their ability to use defensive tactics or less lethal options. Finally, they must consider the ability/willingness of the law enforcement administration to sanction their appearance. The simultaneous assessment of departmental policy, job definition and administration's sanctions on which these bad habits and decisions are made is crucial to understanding and eliminating obesity in law enforcement.

The melting fat concept sees human behavior as controlled by role definition and situations. Different fats melt at different temperatures; hence, some officers define their role incorrectly and behave inappropriately. What controls acceptable human behavior is correct role definition, followed by appropriate behavior (Otu, 2011). When the temperature is incorrectly read, there is going to be an improper response by the fat itself. According to this idea, it is the incorrect role definition that leads to inappropriate behavior. The literature shows that longstanding equal employment laws, coupled with fear of discrimination lawsuits, is creating warfare and handicapping administrators and employers from taking appropriate decisions against obese officers.

For example, Police Chief Paul S. Goward was fired for trying to get his officers to shape-up, by writing and distributing a memo entitled, "Are You a Jelly Belly? As I look around the department, I see a disconcerting number of us that appear physically challenged with obesity and/or a general lack of fitness. This is a tremendous concern to me because the literature, to say nothing of common sense, says that if you are obese or out of shape, you are a predictable liability to yourself, your partner, this department, the city of Winter Haven and the citizens of our city-----“ (Ardell 2006 p. 1). Police Chief is a management position with a function that spreads throughout a department, from frontline Patrol Officers to the Assistant Police Chief. These management roles allow them to exercise some power in the process of achieving organizational goals. It is frontline staff's (Patrol Officers) performance and job definition that should determine police policies, because Patrol Officers deal directly with the citizens (offenders and non-offenders), but in reality it is not always so, Why was Chief Goward fired? 
For example, some police chiefs in this study said it was very difficult to please some politicians and that politicians were determining/creating departmental policies with little or no law enforcement knowledge, hence, police chiefs are just "rubber stamps." In other words, police chiefs must go along with the politician's administrative decision, even though the decision might be administratively wrong.

For the purpose of this paper, we see management as a process that helps direct and mobilize people and their ideas toward organizational goals, (Kotter 1990). The issue of whether or not the police manager should make decision/policies should not be in question. Neither the politicians nor the ordinary citizens are experts in policing. Above all, police chiefs need the support of the politicians (employer) to practice their skills. All law enforcement officials, whether they are chiefs or patrol officers, exist primarily to serve the citizens and they need the support of politicians and citizens to do their job. Society can face a significant risk, if faced with an overweight police officer for help. If a policeman cannot defend himself, how can he defend someone else?

The relationships that police chiefs have with the politicians (employer) can have a "profound" effect on whether officers are required to stay in shape or become obese. Such incidents, as with Chief Goward and many others provide compelling anecdotal evidence that politicians getting involved in Law Enforcement Management is one of the factors motivating officers not to stay in shape, because there are no consequences for being obese.

\section{Theory Implication:}

The findings from this study are consistent with both the "melting fat" concept and the punishment-according-to-culture theory. This study did not conduct direct tests of all the data, but rather used secondary data. However, the findings support the general idea behind the melting fat concept. Defining the roles of police chiefs, subordinate and patrol officers to be role players is very significant in the process of having physically fit officers. Also, the study findings are consistent with the proposition of punishment-according-to-culture theory that only culturally (professionally) appropriate punishment can deter future inappropriate behavior (Otu 2000).

These results support the idea that an effective punishment model should demonstrate some understanding of the values and behaviors considered essential to law enforcement. It is very simple for administrators to set a punishment that fits policing as an occupation and control police officer appearance. Although times have changed, the police roles have not necessarily changed with time. Obesity in law enforcement could be attributed to role ambiguity, civil rights laws, lack of regulatory mechanisms, and training styles. Some police officers are not well trained universally for their jobs, and although all officers must pass a licensing examination in the U.S before they practice, such examinations may only test some part of what is involved in the enforcement of law and may not test continuous physical fitness. Testing of entry officers alone is not a good measure of predicting future success as law enforcement officers.

The unreasonable or total lack of in-service physical training is also another major problem for the law enforcement field. The meaning of personal loyalty to the field, self, the community and colleagues is complex in the law enforcement field. The self-protective (protect your behind) approach of law enforcement agencies is a hindrance to complete loyalty. It is generally known that some entry officers (recruits) only manage to pass the physical fitness examination once at the beginning of their career and never be required to take in-services physical training.

\section{Methods and Participants:}

This study employed a qualitative descriptive method using a semi-structured interview to obtain a description of the experience of being obese and or working with obese/unfit officers. According to Sandelowski (2000), a qualitative description method is very appropriate for this study. It is not easy to obtain data of an embarrassing issue as obesity; hence, this study used purposeful sampling with maximum variation, (Sandelowski, 2000). Obesity is a range of weight that is greater than what is generally considered healthy for a given height, an adult who has a BMI of 30 or higher (Center for Disease Control and Prevention, CDC 2009). A total of 400 individuals were interviewed, including 200 presently obese officers, 180 working former obese officers and 20 obese police chiefs.

Since body weight is a sensitive issue, the researcher decided to obtain data that varies widely, in order to capture both physically fit and obese police officers' different opinions, purposeful sampling with maximum variation according to Sandelowski (2000, p. 338) was used on the Nigerian and the United States of American Police.

A total of 400 individuals were interviewed, 280 men and 120 females. Police officers were selected for the interview by personal observation of the researcher. Officers who appeared to be obese were informally interviewed. Once a possible participant was located, the researcher personally would ask if they would be willing to talk with him about themselves, and in many cases they would agree. It was not necessary to record their names or departments and they were all promised anonymity in all areas. They were very concerned about publicity or anything that might reveal their identity. The data was collected from May 2010 till December 2012.

\section{Interviews:}

This study asked obese police officers to describe their experience from the month that they felt obese, as compared to the time they were newly hired or just out of the police academy. All the officers interviewed were physically fit when they were newly hired. The primary question was described to me; what difference was it from the time you graduated from the police academy up till the period when you became obese and from the period you became obese, until the present. On the specific areas of law enforcement duties, such as apprehension of suspects, use of force, participation in youth 
organizations, stress management, sick time, etc., the researcher did ask follow-up questions to explain, probe further and/or clarify some of the questions/answers. All respondents were interviewed at the location of their preference. One hundred and fifty $(n=150)$ officers were interviewed in their homes. Fifty $(n=50)$ officers were interviewed in a bar. Twenty $(n=20)$ officers (chiefs) were interviewed in their offices, and one hundred and eighty $(n=180)$ officers were interviewed in a park. The officers made written notes of all responses, and the interviews lasted between 30 to 45 minutes. The researcher did express appreciation to the participants and promised confidentiality and anonymity. This data collection technique used minimal to moderate structured, open-ended individual interviews, (Sandelowski, 2000).

\section{Ethical Issues:}

This study was organized and executed on the rules and principles normally used in qualitative research. Using the relativist stance, the investigator builds open, sharing relationships with the investigated, (SA Healthlnfo 2009). All participants were given oral/written information about the study and clearly informed that participation was voluntary. All participants gave their oral consent and were promised complete anonymity, with no identifying code to link them to their identity, which proves to be the appropriate action, (Callahan and Hobbs 1998).

\section{Data Analysis:}

At this stage, the aim was to identify areas of the responses related to providing a description of effects of obesity on health and job performance of police officers. The analysis was done inductively using the principles of descriptive phenomenology, drawing upon the work of Colaizzi (1978), Giorgi (1985), Van Kamm (1969), Hsieh \& Shannon (2005), and interpretive phenomenological approaches carried out in several steps drawing upon the work of Heidegger (1962) and Trondheim (2004).

The number one step was to rewrite the interview verbatim, as was said by the respondents and be more familiar with the content. As I read the transcript, I made notes on it to show my first impression of what the (obese officers) respondents were saying in their responses, keeping in mind, how it relates to obesity, health and law enforcement duties.

The number two step was to make notations on the text that seemed to explain the effect of obesity, on health and law enforcement duties. These relationship units were put together and constituted the units of analysis, representing the exact words of the respondents. The direct verbatim responses were then condensed into shorter sentences, with the same meaning, leaving out unrelated and irrelevant statements. The condensed responses were then coded at a manifest level. The different codes were compared and combined to develop categories and sub-categories with the aim of describing the effect of obesity on health and job performance of a law enforcement officer.

The combination of categories and sub-categories pointing at the effect of obesity on health and law enforcement officers' performance, allows for the development of a chart to further assist in explaining the content of the text. At this point in the process, the codes, categories and sub-categories were compared with similar qualitative descriptive research methodology. The final step was the formulation of the latent content into catalog that answers the research question. I finally compared the findings to both the verbatim responses of the subjects and the coded transcripts of the interview to reconfirm the findings.

\section{Results:}

Obese police officers described themselves as a little bit overweight or choppy. With this theme in mind, of not accepting to be obese, even though their physical appearance convincingly shows they are obese, I allowed concern to remain concern and perceptions remained perceptions (Sandelowski, 2000) and not allow the consequence of their perception of themselves to influence the coding. The informational contents of the data were organized based on the overall theme of two categories (category and sub-category): Experiences (law enforcement) while the officer was at a healthy weight and fit, and while obese and unfit. The sub-categories include health issues, family, friends and eating habits. Below are the findings, presented with some verbatim quotations used to emphasize some points.

\section{Process of Growing from Healthy Weight to Obese Police Officers:}

The entire theme of growing from fit or healthy weight to unfit obese police officers can be clarified as a process extended over a time when officers tend to let down their guards and assimilate into a stage of unofficial socialization or into police subculture. The basic nature of the process was the intent of fitting-in and being comfortable with the new role as a police officer and the aim of gaining acceptance in the sub-culture. These culminated into being too relaxed and not watching "intake" and going with the flow. The issue of staying fit after graduating from the academy was secondary, whereas being among the "boys/girls" was a primary concern of the officers. The ability and determination to return to pre-academy weight was always an unfulfilled promise. All the officers interviewed did acknowledge they were chuppy "obese" in their first two years in service.

Despite it was easy to accept to being a little bit choppy (obese), it was difficult to do something about it. The weight gaining process was influenced by diverse factors that correlated positively or negatively with each other. This uncovered a range of interrelated factors: physical inactivity, police culture, high fat/high calorie diet, genetics, alcohol consumption, smoking, medical problems (emotional or psychological problems) age and gender. 


\section{Physical Inactivity:}

In all, physical inactivity is a common factor in all obese police officers. Some of the obese officers reflected on the fact that the more weight they gained the less active they were. Obese people have a hard time moving and walking may cause pain in the feet, knees, and ankles. Many of the respondents reported being tired quickly and feeling a shortness of breath, "Police work requires very little activity, since we sit in the car and drive most of our work time".

\section{Police Culture:}

The result of this study shows that an unhealthy life-style is related to obesity. Police work offers an opportunity to be obese-getting drive-through burgers, slices of pizza, etc. Almost half of the obese officers interviewed considered themselves light to moderate drinkers and tobacco users. All the obese officers reported one or more unhealthy lifestyles, from binge drinking to daily eating of fast food. All officers interviewed agreed that fast food is the easiest and most convenient means of getting breakfast, lunch and dinner. "Police work is a male dominant occupation and we tend to socialize with alcohol; the culture pressure female colleagues to emulate the heavy drinking habits".

\section{High Fat and High Calorie Diet:}

Fat provides more calories than protein or carbohydrates. Some respondents reflected on the fact that the unpredictability of their job does not allow them to sit down and eat healthy food. All the respondents agreed that they eat-on-the-run, hence fast or fatty food is the norm. This study shows that obesity in police officers results from excessive calorie intake and not enough expenditure of energy. In general, all the obese officers agree that, "I think my main problem of being obese is eating a little too much, lacking enough will power, and not being active enough".

\section{Genetics:}

This study reveals that inherited genetic variation is one of the factors for obesity. There is strong evidence that biological relatives exhibit similarities in maintenance of body weight. In these studies nearly all the respondents either have one or both obese parents. "All members of my family are a little choppy. I guess we have to live with it".

\section{Alcohol and Tobacco Consumption:}

In this study over half the respondents were excessive alcohol drinkers. Excessive drinking among police officers may be the result of policing being a male dominated occupation. Smoking is also prevalent among police officers. Almost half of male and female officers said; "Policing is a boring occupation, especially during the grave-yard shift. Most of us smoke to stay awake".

\section{Medical Problems:}

(Emotional or psychological): Although medical problems may influence eating habits and may result in too much eating, this may lead to obesity. Some people may eat in response to negative emotion, for example anger, sadness and boredom. In this study, there was indication that medical problems were a related factor to the respondents' obesity. 'We all have to pass a psychological test before joining the academy (MMPI). Though we may be a little crazy, but we are not knots".

\section{Age and Gender:}

This study shows that obesity is related with age; the older the individual, the higher the chances of being obese. Although there was no clear trend with respect to age and obesity, more men than women police officers were obese. It is known that as we get older the amount of muscles in our body decrease. The lower muscle mass does show a decrease in metabolism. Human metabolism slows with age, but this study did not reveal a relationship between age and obesity. Although men have more muscles and burn more calories than women, but this study failed to support that assumption for police officers. "Obesity has increased all over the world over the past decades. It is difficult to associate it to gender or age".

\section{Obesity and Police Responsibilities:}

According to the world health organization, obesity is a condition of excess body fat to the extent that health is impaired, (WHO, 2000). Obesity is always associated with other related serious health conditions called comorbid condition, which is defined as any condition associated with obesity that increases the risk of disability and premature death (St. Vincent Stealth, 2006). Obesity is a known risk factor for diabetes, coronary heart disease, high blood pressure, cholesterol, stroke, hypertension, gallbladder disease, osteoarthritis, sleep apnea, and other breathing problems, some forms of cancer, complications of pregnancy, menstrual irregularities, stress incontinence, psychological disorder, and increased surgical risk, (U.S. Department of Health and Human Services 2007). For the purpose of this study, obesity is a range of weight that is greater than what is generally considered healthy for a given height, a BMI of 30 or higher, (Center for Disease Control and Prevention, CDC 2009).

Police officers are law-abiding citizens who wear a uniform to enforce the law (Otu, 1999 p. 3). In the policing field, there is a correlation between physical fitness and job performance. Universally, policing is an occupation that requires officers to 
be physically fit or they would be a danger to themselves, and/or the public. Police work requires good physical ability to satisfactorily perform the following: climbing, jumping, running, lifting, pushing, punching, dragging and use of force, (Smith and Taker 2005). According to the U.S. Federal Bureau of Investigation (FBI) study in 1997, the result shows that, out of 52 officers assaulted, 47 stated that they were in excellent physical health when they were assaulted, and four reported being in better than average physical health. A majority of the officers stated that being in good physical shape aided them to survive assault, (Pinizzotto, Davis, and Miller 1997). According to Collingwood (1998), in seventy-five percent of police arrests, officers described the level of resistance by the suspect as moderate to strong and powerful, and it took between 30 seconds to two minutes to restrain the suspect. For most of the resistance, officers used 75-95 percent of their maximum strength. Being in good physical shape is important to being a successful police officer. "Cardiovascular endurance, anaerobic power, muscular strength, muscular endurance, flexibility and body composition are all underlying factors in successful job performance", (P. 2).

The financial cost for illnesses and diseases associated with police officers being unfit is very high. Lots of illnesses, which law enforcement personnel suffer from are called "modifiable risk factors". These are health conditions and related costs that could be off set by staying fit. For example, heart diseases cost $\$ 183$ billion, diabetes $\$ 100$ billion, cancer $\$ 157$ billion and arthritis $\$ 65$ billion, (Shell 2005). Studies show that 20 percent of a law enforcement department's workforce is responsible for about $80 \%$ percent of the cost of all accidental incidents in their department. The average cost of an inservice heart attack for an average size department is between $\$ 400,000$ and $\$ 700,000$, (Quigley 2008). Heart disease accounts for 20-50 percent of all early retirement, while back pains cost 15-35 percent, and inactivity that leads to obesity is a major factor contributing to all the above conditions, (Smith and Tooker 2005). Studies so far have shown that being physically fit has direct correlation with reducing injuries, improving mental and psychological development, as well as improving work efficiency and effectiveness.

\section{Recommendations:}

"If we believe a thing to be bad, and if we have a right to prevent it, it is our duty to try to prevent it and damn the consequences, (Milner 1909). It is well known that one very important thing that will always help officers the most is being in good physical health. Police officers' obesity problem is a worldwide issue that deserves serious attention. The worldwide concern is reflected in the following:

In the United States; the "Jelly Bellies Memo", and the "Hiring of Dietitian to Arrest Officers' Obesity" in the Los Angeles Police Department are notorious examples of the concerns.

In Thailand, the creation of boot camp and the requiring "Potbellied Thai Police Officers Sent to Boot Camp" is an indication of the seriousness of the issue.

Also, in England, "Obese UK Police Officers Face Pay Cuts" signifies a worldwide emergency situation, (Holden 2011, The Associated Press 2008, Kharchenko 2013).

The above headline activities are the indications that officers' obesity affects every country's police force. It is important that entry-level law enforcement training academies employ enough amounts of hours for physical training as an important part of their requirement to become a police officer. The type of physical training should be relative to the job requirements of a police officer.

Police departments should require fitness training even after the (in-service) academy. Police departments should hire qualified trainers to work with officers after training in the academy. Police officers' physical fitness can be an important area for minimizing liability. The unfit officer would not respond appropriately to strenuous physical attack by suspect, and may resort to using deathly force inappropriately. In the 1988 case of Parker v. District of Columbia, the D C. Police Department was found to be indifferent to the physical training needs of its officers.

Every Police Department should establish fitness and wellness programs.

Studies show that North Carolina State approved funding for seven police departments to participate in an experimental studies and the result shows improvements across the board in physical fitness. There were significant cardiovascular, strength and emotional improvements on many participants. Above all, many participants were able to discontinue their diabetes and hypertension medication. All participating departments reported a reduction in turnover rate, reduction in accidents, reduction in worker's compensation section claims and a 25 percent overall productivity, (Quigley (2008)

With the result of this study, it is the belief of this author that police administrators and policymakers should seriously consider obese officers as a danger to themselves, the public and fellow officers, and do something to help these obese officers. Encourage participation in fitness program, offer to pay fitness program fees, motivate and discuss available options with experts on weight reduction.

\section{Conclusion:}

The result of this study provides evidence, associating obesity with high liability for the police department and job disability, high medical cost and low job performance for obese police officers. The obese police officers turn a solvable problem into a deadly war. Obesity increases the risk of death from any cause and from cardiovascular disease in adults between 25 and 45 years of ages. Available studies agree that policing as an occupation has the highest rate of diabetes, heart disease and suicide. Although unfortunate, it is the reality, and it emphasizes the need and importance of physical fitness for police officers. Even though many police officials may feel that officers have had enough of the constant 
criticism, harassment, uncertainty, and willfully sustained attack by the government and society, the truth is that police officers are visible representation of the government and in some cases, role models for children. If officers are obese, they are sending out the wrong message that it is alright to be obese.

\section{References:}

1. Ardell D. B. (2006) Promoting Fitness Can Be Hazardous to Your Job: A Police

2. chief Gets Fired For Trying To Do The Right Thing. Retrieved April 28, 2013

3. from http://trusted. md/blog/donald-ardell/2006/11/15/promoting-fitness....

4. Blum L. (2008) Key Note Speaker, Annual Memorial Ceremony, Garden Groves, Posted

5. By Greenhut S., Retrieved on March 2013 from

6. http://orangepunch.freedomblogging.com/2008/05/23/garden-grove-cops-told-to- be-less-fr,,,,..

7. Brooks, M. E. Law Enforcement Physical Fitness Standards and Title VII, FBI Law

8. 777 (Summer Enforcement Bulletin (May 2001) citing David E. Hollar, Physical Ability Test VII, 67 Univ. of Chigaco Law Review 2000).

9. Callahan, T. C., Hobbs. R, (1998) Research ETHICS, Retrieved on February 19, 2009

10. from: http://depts.aswhington.edu/bioethx/topics/resrch.html

11. CDC (2009) Center for Disease Control, Defining Overweight and Obesity, Retrieved on

12. April 26, 2013 from http://www.cdc.gov/nccdphp/dnpa/obesity/defining.htm.

13. Colaizzi, P. F. (1978) Psychological research as the phenomenologist views it. In Valle

14. R. King M. (Eds) Existential-Phenomenological Alternatives for Psychology.

15. New York, Oxford Press.

16. Collingwood T.R. (1998) Why officers Need to be fit" chap. 1 in Fit force

17. Administrator guide (Champaign, Illinois: Human Kinetics)

18. Center for disease Control and Prevention (2009) Defining Overweight and Obesity;

19. Retrieved on January 5, 2009 from:

20. http://www.CDC.gov/nccdphp/dnpa/obesity/defining.htm

21. Collingwood T. R. (1995) "Why officers Need to be Fit" in Fit Force Administration

22. guide, champ. Align, see: Human Kinetics.

23. Ebling, P. (2002) Physical Fitness in Law Enforcement Follow the Yellow Brick Road -

24. FBI obstacle course, the FBI Law Enforcement Bulletin, Retrieved on 12/1/08

25. from: http://findarticle/mi-mz194/is-10-71/ai-93915933?+a

26. Geller, G., \& Holtzman N. A (1995) A qualitative assessment of primary care physicians'

27. perceptions about the ethical and social implications of offering genetics testing.

28. Qualitative Health Research. 5, 97-116.

29. Graneheim, U. H \& Lundman (2004) Qualitative Content analysis in nursing research

30. Concepts, procedures and measures to achieve trust-worthiness. Nurse Educ.

31. Today 24(2) 105-12

32. Georgi, A. (Ed)(1985) Phenomenology and Psychological Research. Pittsburgh,

33. Duquesne University Press.

34. Heidegger, M. (1962), Being and time, Oxford, Basil Blackwell

35. Hsieh, H. F \& Shannon, S. E (2005), Three approaches to qualitative Content analysis.

36. Qual Health Res 15 (9) 1277-88

37. Holden M. (2011) Obese UK police officers face pay cuts, Thompson Reuters, Retrieved August 4, 2013 from ukreuters.com/assets/print?aid=UKBRE82EOS120120315.

38. Jurkanin, T. J. (2008), Illinois Law Enforcement Training and Standard Board, Peace 
39. Officer Wellness Evaluation report (Power)

40. Kharchenko G. (2013) Boot Camp Offered in Thailand for Overweight Police Officers,

41. PRWeb Online VisibilityfromVocus Retrieved August 4, 2013 from

42. www.prweb.com/printer/10903640.htm.

43. Krueger R. A, Casey M. A. (2000) Focus groups: a practical guide for applied research

44. $3^{\text {rd }}$ ed. Thousand Oaks, Calif: Sage Publications.

45. Milner L. (1909)The Peers and the Budget, Speech at Glasgow, 26 November.

46. Otu N. (2011) Violence from within: Doctors Vs. Nurses. The Online Journal of Health

47. Ethics, 7 (1)

48. Otu N. (2000) Let Punishment and Treatment Fit the Culture, The Justice Professional

49. $12,253-275$.

50. Otu N. (1999) Colonialism and the Criminal Justice System In Nigeria; International

51. Journal of Comparative and Applied Criminology and Criminal Justice, Vol. 23 \#

52. 2 293-326

53. Parker V. District of Columbia 850 F-2d- 708 (D. C. Cir. 1988)

54. Pinizzotto A F, Davis E. F. and Miller C. (1997) In the line of Fire, Washington D.C., 55. Department of Justice, Federal Bureau of Investigation 14.

56. Quigley A. (2008) Fit for Duty? The Need for Physical Fitness Programs for Law

57. Enforcement officers. The police chief, vol. LXXV, No. 6, June 2008

58. Reeves, G. (2006) "Fat memo" gets former KS cop fired in FL., (AP) FL Winter Haven

59. Retired on 12/1/2008 from: http: //blog.Kansascity.com/crime-scene/2006/11/fat-

60. memo-gets-f.html

61. Shell, D. E (May, 2005) Physical fitness: Tips for the law enforcement executive, The

62. FBI Law Enforcement Bulletin, Retrieved on 12/1/2008 from:

63. http://findarticles/mi-m2194/is-/ai-n13826305

64. Sandelowski, M. (2000) Whatever happened to qualitative description? Res Nurs Health

65. 23 (4) 334-40

66. SA Healthlnfo (2009) Ethics issues in qualitative research, Retrieved on February 9,2009

67. from: http://www.sahealthinfo.org/ethics/ethicsqualitative.htm

68. Smeltzer, S. C (1994) The concerns of pregnant women with multiple Sclerosis.

69. Qualitative Health Research 4, 480-502.

70. St. Vincent Health (2006) Bariatric weight Loss Center of Excecl, Retrieved on February

71. 27, 2009 from http://www.Stvincent. org/ ourselves barratrously default.

72. Smith J. E. and Tooker (2005) Health and Fitness in law Enforcement? A voluntary

73. Model Program Response to A critical Issue, CANEA update, no 87628),

74. Retrieved on February 27, 2009 from http://www.coalea.org/online.news letter Ino 87/ health fitness. htm

75. The Associated Press (208) Dietitian hired to arrest officer obesity, NBCNews.com,

Retrieved August 4, 2013 from www.nbcnews.com/id/24488611/ns/health-

77. diet and nutrition/t/dietitian-hired-arrest-officer-obesity/\#Uf6WxtlU-zl.

78. USLEGAL (2009) Focus Group Law \& Legal Definition, Retrieved on February 18,

79. 2009 from: http://definitions.uslegal.com/f/focus-groups/

80. U.S. Department of Health and Human Services (2007) Statistics Related to overweight 
81. and obesity, Retrieved on February 22, 2009 From http://win.niddk.nih. gov/statistics.index.htm.

82. Van Kamm A. (1969) Existential Foundation of Psychology, New York, Doubleday.

83. World Health Organization (who) (2000), Obesity: Preventing and managing the Global

84. epidemic Report of \#1110 Consultation, Geneva, Switzerland: (Technical re port

85. Series no 894) 